\title{
DEVELOPING INTERACTIVE MULTIMEDIA MATERIAL TEXT RECOUNT ORAL AND WRITE ABOUT SIMPLE EXPERIENCES FOR EFL STUDENTS
}

\author{
Purwo Trapsilo \\ purwo.trapsilo@kumala.ac.id \\ Faculty of Teachers Training and Education Science \\ STKIP Kumala Lampung Metro
}

\begin{abstract}
The aims of research are: (1) to describe the condition and potency of current learning on the basic material text recount, (2) to produce teaching-learning materials Compact Disc (CD) interactive multimedia which is integrated with basic competence in the form of procedural text with manuals and tipsand it was conducted at one semester students EFL Data were collected through observation, questionnaires, and tests. Analyze data uses descriptive and Gain test. The conclusions of research are; (1) EFL has the potency of using IT, tools and infrastructure of computer, teaching material to support the teaching process, (2) the process produced the product through Lectora program, (3) The teaching and learning process utilizing interactive multimedia teaching material is more effective, shown by $\mathrm{N}$-Gain score 0.71, (4) after using interactive multimedia, the teaching and learning process can save 90 minutes compared to the previous lesson, (5) learning using interactive multimedia interesting, in organizing strategy $(87.00 \%)$, in terms of delivery $(84,97 \%)$, and in terms of program management strategies to obtain optimal learning results $(85.04 \%)$.
\end{abstract}

Keywords: Interactive Multimedia, Teks Recount, English.

\section{INTRODUCTION}

This type of research is the Research and Development (R \& D). Borg \& Gall ( 2006) explains that the development of research-oriented research to develop and validate the products are used in education $\mathrm{R} \& \mathrm{D}$ collaboration with suppliers offers more limited new knowledge, but it is still useful for product innovation because it differs from the firm's existing knowledge. Knowledge obtained from collaborating with suppliers is narrow because in many cases they and the focal firm operate in the same or similar industries (Gall, Gall, \& Borg, 2006). 
Current conditions in the learning activities: a) the teacher still dominates in the learning process, b) teaching material used is limited to textbooks and Worksheet Students, c) there is no other media used in the learning process, especially computerbased media, d) the results of student learning, especially in the Basic Competency material text recount oral and write about simple experiences, activities is still likely to be low below the minimum completeness criteria, have reinforced the results of final exams 1 ECD school year from 42 students 79 reached only $26.58 \%$ or as many as 21 students. The following student achievement SMK ACI in the academic year 2016/ 2017.

A multimedia instructional message is communication using words and pictures that is intended to promote learning. For example, a multimedia instructional message in a book could include printed text and illustrations, whereas a multimedia instructional message on a computer could include narration and animation. Examples of multimedia instructional messages include words and pictures intended to explain how lightning storms develop, how car braking systems work, and how bicycle tire pumps work. (Mayer, 2014b)

Interactive multimedia on the frame of the use of computer-based media. They stated that multimedia is a combination of text, graphics, sound, animation, and video. When users get flexibility in controlling interactive multimedia. These include the multimedia principle (using both words and pictures), the coherence principle (avoiding extraneous media), the modality principle (using narration rather than text), the spatial contiguity principle (placing words and pictures close together), and the temporal contiguity principle (presenting words and pictures at the same time). The empirical evidence for these principles is strong(Evans \& Gibbons, 2007).

Definition interactive multimedia that has been raised that among other media interactivity the user must press a keyboard or click with the mouse to move the page (display) or enter answers of an exercise or test and computer to give correct answers through feedback (feedback). In line with the opinion states that the teaching material is any material (whether information, tools, and text) are arranged systematically, the 
figures show full of competencies to be mastered and used learners in the learning process with the objective of for the planning and implementation of learning research. (Rasch \& Schnotz, 2009).

This study aims to (1) describe the condition and potential of interactive multimedia in the process of learning English, (2) to produce interactive multimedia, (3) test the effectiveness of interactive multimedia, (4) test the efficiency of interactive multimedia, (5) to test the attractiveness of interactive multimedia.

A multimedia summarizer system for retrieving relevant information from some web repositories based on the extraction of semantic descriptors of documents. In particular, semantics attached to each document textual sentences is expressed as a set of assertions in the 〈subject, verb, object) shape as in the RDF data model. While, images' semantics is captured using a set of keywords derived from high-level information such as the related title, description, and tags(Damiani, Howlett, Jain, Gallo, \& De Pietro, 2015).

A multimedia instructional message is a communication containing words and pictures intended to foster learning. The communication can be delivered using any medium, including paper (i.e., book-based communications) and computers (i.e., computer-based communications), or even face to face (i.e., face-to-face communications)(Mayer, 2014a).

Many design features of multimedia materials, such as colors,shapes, and sounds, are likely to have an impact on learners' affect, yet few theoretical models of multimedia learning consider the effect of emotions on learning. Multimedia learning can, for the purpose of this research, be defined simply as learning from pictures and words(Um, Plass, Hayward, \& Homer, 2012).With technological development, interactivity has been introduced with videos being played from a laserdisc controlled by some computer that make use of the random-access capability of the laserdisc player and allow a viewer to select random modules of content. This capability empowered the users to control the path and flow of content, while bypassing superfluous topics. With hyperlink and hypermedia interface a user can navigate through into the subject areas of his/her interest(Rowe, 2011). 
Over all, the objectives of the current study are:

(1) to describe the condition and potency of current learning on the basic material text recount

(2) to produce teaching-learning materials Compact Disc (CD) interactive multimedia which is integrated with basic competence in the form of procedural text with manuals and tips, Multimedia is expected to be a teaching aid tool that will make learning effective because multimedia is a combination of visual, audio, and audiovisual elements; like images, text, sound, animation, and video.

\section{METHOD}

\section{Design}

This type of research is the Research and Development (R \& D). Borg \& Gall ( 2006) explains that the development of research-oriented research to develop and validate the products are used in educationR\&D collaboration with suppliers offers more limited new knowledge, but it is still useful for product innovation because it differs from the firm's existing knowledge. Knowledge obtained from collaborating with suppliers is narrow because in many cases they and the focal firm operate in the same or similar industries(Gall et al., 2006).

Nevertheless, the knowledge provided by a supplier is useful, because it is part of a specialized set of skills possessed by the supplier and not the focal firm. Most of the literature argues that R\&D collaborations with suppliers are beneficial for product innovation because of the combination of complementary capabilities and the common goals between firm and suppliers. Buyers can benefit from involving suppliers early in the development process in terms of time-to market of new products, development cost, and product quality and $\operatorname{cost}(\mathrm{Un}$, Cuervo-Cazurra, \& Asakawa, 2010). 
WEJ, Vol 3 No 2 September 2019

\section{Participant}

Subjects or participant of this study consisted of students, teachers, and media experts, subject matter experts and instructional design experts. The subject of research students who were included in the study analysis of the product needs amounted to 42 students SMK ACI, while on a small group test 18 students from three schools of research subjects, namely 6 students of English Location language. At the stage of product needs analysis study, research subjects totaling 3 Lecturer SMK ACI with the same background of teaching subjects. Experts involved in product testing results.

\section{Instrument}

a) Interview (Interview)

Interviews are used as data collection techniques if researchers want to conduct preliminary studies to find problems that must be studied and also if researchers want to know things from respondents who are more in depth and the number of respondents is small / small. Interviews can be conducted in a structured manner (researchers have known for certain about what information will be obtained) or unstructured (researchers do not use interview guidelines that have been arranged systematically and completely as data collectors) and can be done directly (face to face) or not directly (via media such as telephone).

b) Questionnaire (Questionnaire)

Questionnaire is a technique of data collection conducted by giving a set of questions or written statements to the respondent to answer. And it is an efficient data collection technique if the researcher knows for sure the variables to be measured and knows what is expected from the respondent. The questionnaire is also suitable if the number of respondents is quite large and spread over a wide area. 


\section{Data Collecting Technique}

The initial step in conducting research of this development is to conduct a preliminary study, there are two activities that carried out in this preliminary study, namely: (1) a literature review and (2) analysis of needs. In the event, a literature review, which examined is in the form of literature relating to the theory, concepts and research findings that are relevant to support the preliminary study. Activity analysis of the product needs, aims to determine the condition and potential to the possibility of products that will be developed, the instruments used for this purpose a questionnaire (shown in Appendix 14) were distributed to the research subjects are students and teachers, the determination of the teacher as respondent determined by purposive sampling is sampling with particular objectives and considerations.

The feasibility study carried out by conducting a field survey on the availability of infrastructure such as computers become a requirement of this product development. The survey was conducted mainly existing school environment in the metro city The second phase of product development.

\section{Data Analysis Technique}

Based on the data obtained from the results of preliminary studies and then consulting with partners, the results of these discussions are expected to be a clear picture of the product specifications will be developed along with its supporting device. Procedurally research activities on the development stage include: (1) the initial product development, (2) develop a package of teaching materials, (3) expert validation test, and (4) Test field.

After the program package so, then the next step is the testing of products in the form of interactive multimedia development in the learning process. Test deployment product development results in the learning process and learning English is to determine: (1) The effectiveness of the application of the product, namely the extent to which this product can improve processes and student learning outcomes, 
(2)Efficiency of use of the product associated with the management of resources used in interactive multimedia, and (3) The appeal or attractiveness of the product.

Learning efficiency as measured by various resources needed, how much the cost and how long it takes to achieve specified learning goals. Test the attractiveness of the product, aims to determine the attractiveness and ease of use of the product. Indicators marked with the attractiveness of the product development results repeatedly by students, it is because it is supported ease of use to test the attractiveness of the product used a questionnaire compiled by the Likert scale. Likert scale is a scale that can be used to measure attitudes, opinions, and perceptions of a person or group of people about a symptom or educational phenomena. It is also reinforced with some relevant research studies(Clark, Nguyen, Sweller, \& Baddeley, 2006).

\section{RESULT AND DISCUSSION}

The eligibility of teaching materials is obtained from the validation and assessment given by the material and design experts. The process to obtained the eligibility of the teaching materials is divided into two, namely the material eligibility and design eligibility. For material feasibility, the validated aspect includes: 1) feasibility of content, 2) feasibility of presentation, 3) language feasibility, and 4) feasibility of graphics. As for the feasibility of teaching materials design, the aspect being assessed is the feasibility of graphics. The process of determining the feasibility of developed teaching materials can be seen in the following table.

\section{Content Eligibility}

The acquisition score on each content feasibility subcomponent can be seen in the following table. 
Table1. Percentage of Assessment on Every Sub Component of Content Eligibility

\begin{tabular}{|c|c|c|c|}
\hline No & Sub Component Assessment & Average(\%) & Criteria \\
\hline 1 & Material suitability with KIand KD & $91,67 \%$ & Very good \\
\hline 2 & Material accuracy & $91,07 \%$ & Very good \\
\hline 3 & Material upgrades & $90,62 \%$ & Very good \\
\hline 4 & Encourage curiosity & $81,25 \%$ & Very good \\
\hline \multicolumn{2}{|c|}{ Average } & $\mathbf{8 9 . 8 4 \%}$ & Very good \\
\hline
\end{tabular}

The result of the percentage of material experts on the content eligibility above shows that the sub-component of the assessment of material conformity with $\mathrm{KI}$ and KD has an average percentage of $91.67 \%$, the accuracy of the material with an average of $91.07 \%$, the material content with an average of $90,62 \%$, and encourage curiosity with an average of $81.25 \%$. The average percentage outcome of the overall sub-component of the assessment of the feasibility aspect of the content presentation was $89.84 \%$ with the criteria of "very good."

To produce teaching-learning materials Compact Disc (CD) interactive multimedia which is integrated with basic competence in the form of procedural text with manuals and tips, Multimedia is expected to be a teaching aid tool that will make learning effective because multimedia is a combination of visual, audio, and audiovisual elements; like images, text, sound, animation, and video(Mayer, 2014a).

This type of research is the Research and Development (R \& D). Borg \& Gall ( 2006) explains that the development of research-oriented research to develop and validate the products are used in education $R \& D$ collaboration with suppliers offers more limited new knowledge, but it is still useful for product innovation because it differs from the firm's existing knowledge. Knowledge obtained from collaborating with suppliers is narrow because in many cases they and the focal firm operate in the same or similar industries(Gall et al., 2006).

These students were not able to make effective use of the multimedia aspects. In terms of the task set, much of the information that was available through the CDROM was not used because students appeared to have no skills or knowledge in 
seeking and recording information from other than textual sources. The accessibility of text printouts meant that students couid delay making the effort to 'read' and understand the information they could receive.

There are three aspects that are tested relating to the newly created interactive multimedia, among others: media design, text material shaped procedures manual and tips and instructional design, each aspect will be asked of his response to media experts, subject matter experts, and design experts.

In the small group trial, there was some feedback so these media are not eligible to be tested further after the revision class product testing is limited. After some input from the trials carried out, the field test either component of the layout, systems and improved teaching materials as much as possible so that the interactive multimedia approach toward perfection.

Product development results after several revisions through expert validation, the next step is the testing of the product to the user group in this case students and teachers aim is to find out the weaknesses and shortcomings of the product developed.

To determine the effectiveness of interactive multimedia in the learning process utilized a test instrument in the form of learning outcomes. Test the effectiveness of these media design uses one group pre-test - post test. To determine the ability of the student researchers conducted field tests using N-Gain statistical calculations with large values of $\mathrm{N}$-Gain $=0.70$ according to the classification by Hake indicated in the table it is known that N-Gain normalized values are in moderate classification, the level of effectiveness is effective, it can be concluded that the effectiveness of the improvement of learning ability after using interactive multimedia program is greater than the prior learning using interactive multimedia program.

Test the efficiency of the product aims to determine how developed interactive multimedia capable of managing learning resources so as to leave plenty of time for students to learn not only in class but can be studied independently. In this 
study, the measurement of the efficiency of product development results completed whole learning materials researchers post-test. Show a success, if a lack of compatibility between the expected.

Test the attractiveness of the product, aims to determine the attractiveness and ease of use of the product. 40 research subjects were asked to rate in terms of organizing strategies, strategy In terms of delivery and management of learning strategies in the use of an interactive multimedia program, there are 15 items to questions related to power tests product appeal. Based on the recapitulation of the questionnaire and then test percentages.

\section{CONCLUSION}

Based on the issues raised in the introductory chapter and in accordance with the purpose of research which has been formulated concluded matters as follows:

a. The use of instructional media average SMK ACI Metro has been widely used, only Interactive Multimedia integrate it into the learning process has not been done.

b. The creation of a media product development results in the form of interactive multimedia learning materials in the form of text manual procedures and tips English based on the analysis of the condition and learning potential.

c. The effectiveness of capacity building for English language learning using interactive multimedia

learning result there is an increase of $70 \%$ before and after the product is used.

d. The level of efficiency of the product is determined, based on the concept of maximizing more time to learn, rationally based on the time used and time required result $2>1$, then the product

efficiently.

The attractiveness of the product development results is measured by indicators of the attractiveness characterized by learning English text material shaped manual procedures through the medium of interactive multimedia learning interesting and easy to use. 
WEJ, Vol 3 No 2 September 2019

\section{BIO-PRIFILE}

Purwo trapsilo is a lecturer at the English education study program of STKIP Kumala Lampung Metro. He graduated from an University Terbuka in 2012 in an elementary school teacher education program, then he took the education technology masters field at Universitas Negeri Lampung. His research interests are English language teaching, professional development. His corresponding email: purwo.trapsilo@kumala.ac.id 


\section{REFERENCES}

Clark, R. C., Nguyen, F., Sweller, J., \& Baddeley, M. (2006). Efficiency in learning: Evidence-based guidelines to manage cognitive load. Performance Improvement. https://doi.org/10.1002/pfi.4930450920

Damiani, E., Howlett, R. J., Jain, L. C., Gallo, L., \& De Pietro, G. (2015). Intelligent Interactive Multimedia Systems and Services. In Smart Innovation, Systems and Technologies. https://doi.org/10.1007/978-3-319-19830-9

Evans, C., \& Gibbons, N. J. (2007). The interactivity effect in multimedia learning. Computers and Education. https://doi.org/10.1016/j.compedu.2006.01.008

Gall, M. D., Gall, J. P., \& Borg, W. R. (2006). I dentifying a Research Problem and Question, and Searching. Educational Research: An Introduction.

Mayer, R. E. (2014a). Cognitive theory of multimedia learning. In The Cambridge Handbook of Multimedia Learning, Second Edition. https://doi.org/10.1017/CBO9781139547369.005

Mayer, R. E. (2014b). Multimedia Learning. The Annual Report of Educational Psychology in Japan. https://doi.org/10.5926/arepj1962.41.0_27

Rasch, T., \& Schnotz, W. (2009). Interactive and non-interactive pictures in multimedia learning environments: Effects on learning outcomes and learning efficiency. Learning and Instruction. https://doi.org/10.1016/j.learninstruc.2009.02.008

Rowe, N. C. (2011). Digital Multimedia. In Multimedia Technologies. https://doi.org/10.4018/978-1-59904-953-3.ch002

Um, E. R., Plass, J. L., Hayward, E. O., \& Homer, B. D. (2012). Emotional Design in Multimedia Learning. Journal of Educational Psychology. https://doi.org/10.1037/a0026609

Un, C. A., Cuervo-Cazurra, A., \& Asakawa, K. (2010). R\&D collaborations and product innovation. Journal of Product Innovation Management. https://doi.org/10.1111/j.1540-5885.2010.00744.x 